\title{
Experimental Investigation of the Fatigue Behavior of Basalt Fiber Reinforced Polymer Grid-Concrete Interface
}

\author{
Bo Wen $\mathbb{D}^{1},{ }^{1}$ Chunfeng Wan $\left(\mathbb{D},{ }^{1}\right.$ Lin Liu $\mathbb{D},{ }^{2}$ Da Fang, ${ }^{1}$ and Caiqian Yang ${ }^{1,3}$ \\ ${ }^{1}$ Southeast University, Key Laboratory of Concrete and Prestressed Concrete Structure of Ministry of Education, \\ Nanjing 210096, China \\ ${ }^{2}$ Hohai University, Key Laboratory of Coastal Disaster and Defence, Ministry of Education, Nanjing 210098, China \\ ${ }^{3}$ Xiangtan University, College of Civil Engineering \& Mechanics, Xiangtan 411105, China \\ Correspondence should be addressed to Chunfeng Wan; wan@seu.edu.cn
}

Received 23 December 2019; Accepted 27 March 2020; Published 23 April 2020

Academic Editor: Guoqiang Xie

Copyright (c) 2020 Bo Wen et al. This is an open access article distributed under the Creative Commons Attribution License, which permits unrestricted use, distribution, and reproduction in any medium, provided the original work is properly cited.

\begin{abstract}
Fatigue behavior is an important factor for mechanical analysis of concrete members reinforced by basalt fiber reinforced polymer (BFRP) grid and polymer cement mortar (PCM) and plays a critical role in ensuring the safety of reinforced concrete bridges and other structures. In this study, on the basis of the static loading test results of concrete specimens reinforced by BFRP grid and PCM, a series of fatigue tests with different loading levels were conducted on interfaces between BFRP grid and concrete to investigate the fatigue behavior of BFRP grid-concrete interfaces. The test results indicate that with high loading level, the fatigue failure mode of interface is interfacial peeling failure while it transforms to the fatigue fracture of the BFRP grid under low loading level. The fatigue life $(S-N)$ curves of BFRP grid-concrete interface are obtained and fitted in stages according to different failure modes, and the critical point of the two failure modes is pointed out. The relative slip evolution of interface during fatigue is further revealed in different stages with two failure modes, and the law of interface strain is studied with the increase of fatigue times. The relation of effective bonding length of interface and fatigue times is also described.
\end{abstract}

\section{Introduction}

Fiber reinforced polymer (FRP) is widely used in the reinforcement and repair of reinforced concrete structures owing to its numerous advantages (e.g., light weight, high strength, high environmental resistance, and strong designability) [1]. Commonly used FRP materials in engineering structures include carbon fiber reinforced polymer (CFRP), glass fiber reinforced polymer (GFRP), aramid fiber reinforced polymer (AFRP), and basalt fiber reinforced polymer (BFRP). Among them, BFRP is a pure natural environmentfriendly inorganic material with excellent mechanical and durability properties, such as high ultimate strain and good ductility $[2,3]$. There is a good application prospect for this material in structure building, reinforcement, and repair of old structures.

FRP cloth and FRP sheet adhered to the outer side of concrete are the most common methods to strengthen concrete structures with FRP [4]. FRP and concrete rely on organic polymer interface adhesives (e.g., epoxy resin) for external surface reinforcement. The key to evaluating the FRP reinforcement effect is to assess whether stress can be effectively transmitted between the concrete and FRP. The interface behavior between FRP and concrete has therefore been the focus of many studies and applications to ensure efficient improvement of structural performance $[5,6]$. Organic polymer adhesives such as epoxy resins have particular disadvantages including rapid aging and poor environmental corrosion resistance. Previous studies have used inorganic materials (e.g., modified cement, fiber cement-based materials, and polymer mortar) as an interface adhesive in place of epoxy resin to improve durability of the FRP-concrete interface [7-10]. The combination of FRP grid and polymer mortar for structural strengthening improves component stiffness with better durability compared with traditional external FRP cloth and is more suitable for harsh reinforcement environments [11-15]. 
The reinforcement system of FRP grid and polymer mortar is applied in concrete structures under long-term repeated loads (e.g., highway and railway bridges, offshore platforms, and underwater structures) that ultimately undergo fatigue failure. The fatigue behavior of FRP gridreinforced concrete structures is closely related to the bonding fatigue performance of the FRP grid-concrete interface, which therefore merits its detailed study. Previous experimental studies on FRP grid-concrete interfaces have included single-lap shear tests [16-18], double-lap shear tests $[19,20]$, tensile property measurements of FRP grid-polymer mortar specimens [21-24], flexural performance measurement of grid-reinforced beams and slabs [25-29], and shear performance measurement of FRP grid-reinforced beams $[30,31]$ and walls [32-34]. These studies were conducted under different static loading conditions to analyze the bonding properties and failure modes of the FRP gridconcrete interface with variable layer numbers, fabric types, bond widths and lengths, temperatures, and other environmental conditions. However, fatigue performance tests on FRP grid-concrete interfaces are scarcely reported and their fatigue behavior remains poorly understood.

In this study, we performed experiments on the fatigue behavior of the FRP grid-concrete interface under different stress level conditions on the basis of static loading test results to analyze the failure modes, obtain failure life $(S-N)$ expressions, and investigate the relative slip behavior of the interface. We use the results to further analyze the law of strain evolution of FRP grid-concrete interfaces during fatigue and the change of effective bonding length.

\section{Materials and Methods}

2.1. Sample Preparation. Concrete specimens were commercial concrete C40 with a section size of $150 \times 250 \mathrm{~mm}$ and length of $400 \mathrm{~mm}$. The longitudinal steel bars at the bottom were $2 \mathrm{C} 16$ and the auxiliary steel bars at the top were equipped with 2C10. The stirrups were bundled with A10@ 300 at a distance of $50 \mathrm{~mm}$ from both ends of the specimens with a protective layer thickness of $20 \mathrm{~mm}$ (Figure 1). During the pouring process, six cubes were randomly selected as standard specimens for compressive strength tests. The dimensions of the cube specimens were $150 \mathrm{~mm} \times 150 \mathrm{~mm} \times 150 \mathrm{~mm}$, in accordance with the Chinese design specification of concrete structures [35]. These specimens were placed under conservation conditions of constant temperature $\left(20 \pm 2^{\circ} \mathrm{C}\right)$ and relative humidity of $95 \%$ or higher. After 28 days of curing, the mean compressive strength of these cubes was measured as $45.1 \mathrm{MPa}$.

The concrete specimens were reinforced by BFRP grid and polymer mortar. The BFRP grid is produced by Jiangsu Green Materials Vally New Material Technology \& Development Co., Ltd, which uses continuous basalt untwisted yarn as raw material. The raw material was formed into a grid, infiltrated with resin, and then dried for shaping. A bidirectional square grid with a thickness of $3 \mathrm{~mm}$ and mesh size of $50 \times 50 \mathrm{~mm}$ was adopted. Each BFRP grid specimen had a width of $150 \mathrm{~mm}$ and length of $800 \mathrm{~mm}$ (Figure 2).

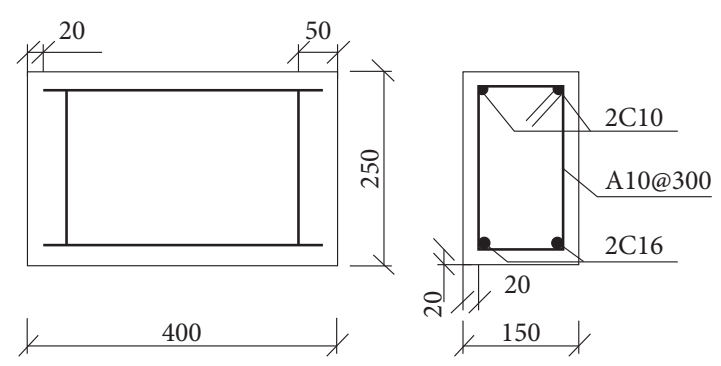

FIgURE 1: Size and reinforcement diagram of concrete specimen (unit: $\mathrm{mm}$ ).

To obtain the material parameters of the BFRP grid, five axial tensile specimens of BFRP grid were prepared with the same size as the single grid specimen (Figure 2) with a nominal cross-sectional area of $36 \mathrm{~mm}^{2}$. The two ends of the tensile specimens were anchored by bonding of four layers of FRP cloths evenly pasted on each side to ensure that the BFRP grids were uniformly loaded. These FRP cloths were applied at $45^{\circ}$ to the loading direction to provide a soft interface, as recommended by the standard test method (ASTM D3039/D3039M-17) [36]. The anchoring length of FRP cloths was $200 \mathrm{~mm}$. The adhesive colloid was Sanyou epoxy resin with a 2:1 ratio of resin to curing agent. Axial tensile tests were conducted according to the standard test method for tensile properties of thin plastic sheeting (ASTM D882-18) [37]. The following results were obtained: the mean tensile strength of the BFRP grid was $583 \mathrm{MPa}$, the average elastic modulus was $38 \mathrm{GPa}$, and the mean elongation was $1.46 \%$. The related axial tensile stress-strain curves are shown in Figure 3(a). All five BFRP grid specimens exhibited linear variation under axial tensile loading, and the final failure mode was tensile failure of the longitudinal tensile fiber ribs (Figure 3(b)). The mortar was polymer-modified cementitious mortar for structural strengthening produced by Hunan Goodbond Co., Ltd., which was a two-component cement-based composite material modified with polymer emulsion. Under constant temperature $\left(20 \pm 2^{\circ} \mathrm{C}\right)$ and relative humidity (>95\%) conditions, the measured compressive strength after 28 days was 46.1 MPa, the flexural strength was $11.5 \mathrm{MPa}$, and the tensile bonding strength with the concrete was $2.7 \mathrm{MPa}$.

When the concrete structure is reinforced by FRP grid and polymer mortar, the effective stress transmission of FRP grid and concrete interface depends mainly on the bonding stress between the (i) concrete and mortar and (ii) mortar and FRP. To ensure optimal bonding performance, detailed steps of BFRP grid-reinforced concrete preparation procedure are as follows. (1) The concrete surface that has been cured for 28 days is chiseled to a depth of $\sim 2 \mathrm{~mm}$ to remove the weak surface layer and expose the solid concrete. (2) Thin wood boards are used to install templates around the reinforced surface of the concrete. (3) The configured polymer mortar is completely wetted on the concrete surface with a thickness of $1 \mathrm{~mm}$. (4) The BFRP grid is installed. Rivets are not used for temporary fixing owing to the small specimen size and paste area $(150 \times 400 \mathrm{~mm})$. (5) The polymer mortar is applied on the grid surface and a spatula is 


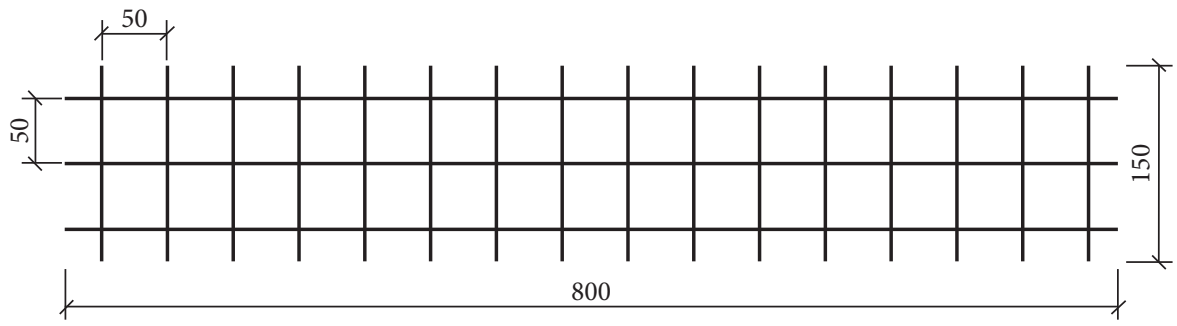

Figure 2: BFRP grid (unit: $\mathrm{mm}$ ).

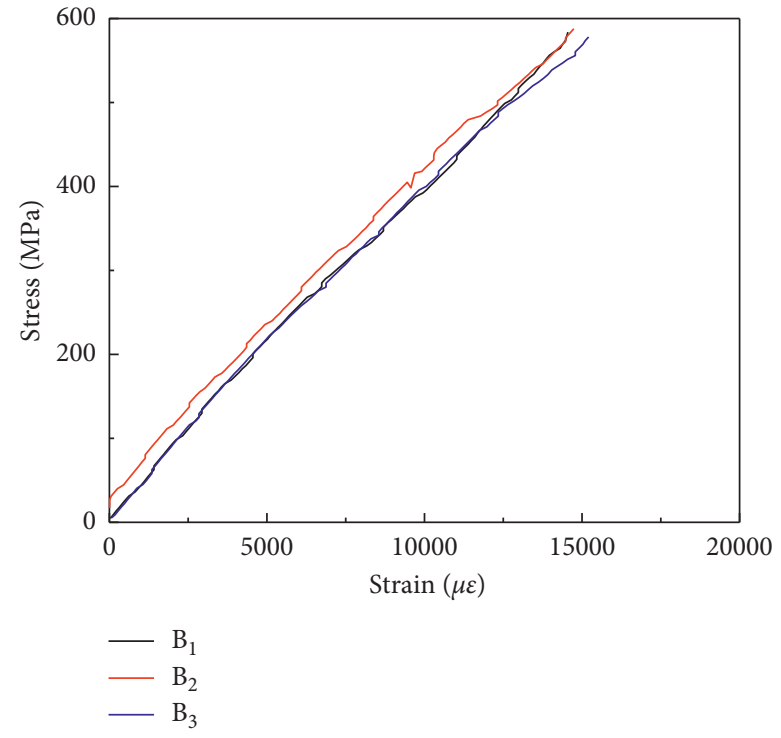

(a)

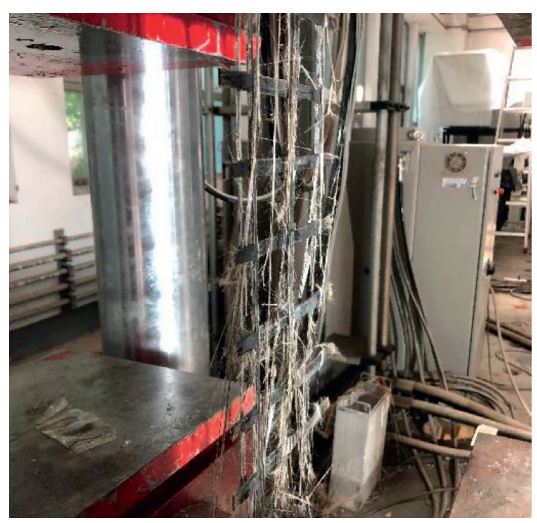

(b)

FIGURE 3: Axial tensile stress-strain curves and failure modes for the BFRP grids. (a) Stress-strain curves. (b) Failure modes.

used for filling, compacting, and smoothing. The mortar layer thickness is held fixed at $\sim 20 \mathrm{~mm}$. The above preparation process is schematically illustrated in Figure 4. After completion of these steps, the specimen is covered with a thin film, watered after one day, and cured for 28 days.

2.2. Experimental Procedure. A servohydraulic dynamic fatigue testing system was used in the tests. The reinforced concrete specimen was fixed between the upper and lower steel plates by screws. The lower steel plate was connected to the instrument by an anchor bolt. The center of the upper steel plate was slotted to protrude the unbonded end of the BFRP grid. The end was anchored by the same method as that of the anchoring method of axial tensile specimens of the BFRP gird, which was convenient for clamping and loading of the instrument chuck. The specimen installation is shown in Figure 5.

Both static loading and fatigue loading were controlled by force. The loading rate of static loading was $10 \mathrm{kN} / \mathrm{min}$ until the specimen failed. In the fatigue tests, before the fatigue loading, static loading was performed twice from 0 to the upper limit $\left(P_{\max }\right)$ of the fatigue loading and then unloaded to 0 . The fatigue loading changed following a sine law with a loading frequency of $5 \mathrm{~Hz}$. For all the fatigue specimens, the lower limit $\left(P_{\min }\right)$ of the fatigue loading was taken as $15 \%$ of the peak static loading $\left(P_{u}\right)$. The upper limit of the fatigue loading was, respectively, taken as $0.84 P_{u}, 0.80$ $P_{u}, 0.76 P_{u}, 0.72 P_{u}, 0.68 P_{u}$, and $0.64 P_{u}$ for six groups of specimens, which was in accordance with the standard test method (ASTM D3479/D3479M-12) [38]. To obtain the strain rule of BFRP grid under static and fatigue loading, resistance strain gauges $\left(G_{1}-G_{8}\right)$ were sequentially arranged at an equal distance of $50 \mathrm{~mm}$ along the middle of the BFRP grid in the bonding area. A strain gauge $G_{0}$ was arranged in the middle of the nonbonding area between the loading anchoring end and bonding area. A detailed arrangement of the strain gauges is shown in Figure 6. The entire test procedure of fatigue test was controlled by an electro-hydraulic servo test system. The loading value was measured in real time by a force sensor, and a multi-channel data acquisition system was used to monitor the real-time strain data of $G_{0}-G_{8}$.

\section{Results and Discussion}

3.1. Static Loading Tests. The loading-BFRP grid slip curve of the specimens under static loading and the specimen failure 


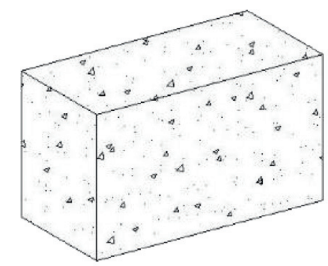

Concrete specimen

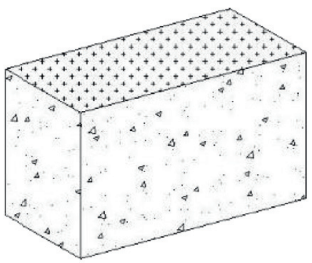

(1) Removing the weak surface layer

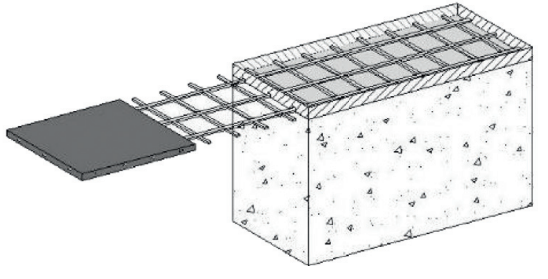

(4) Installation of BFRP grid

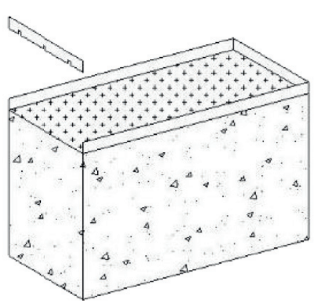

(2) Installation of templates

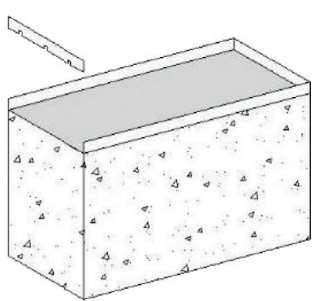

(3) Polymer mortar wetted on the concrete surface

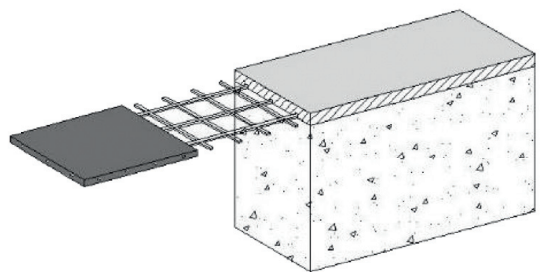

(5) Filling, compacting, and smoothing of polymer mortar

Figure 4: Preparation process of specimens.

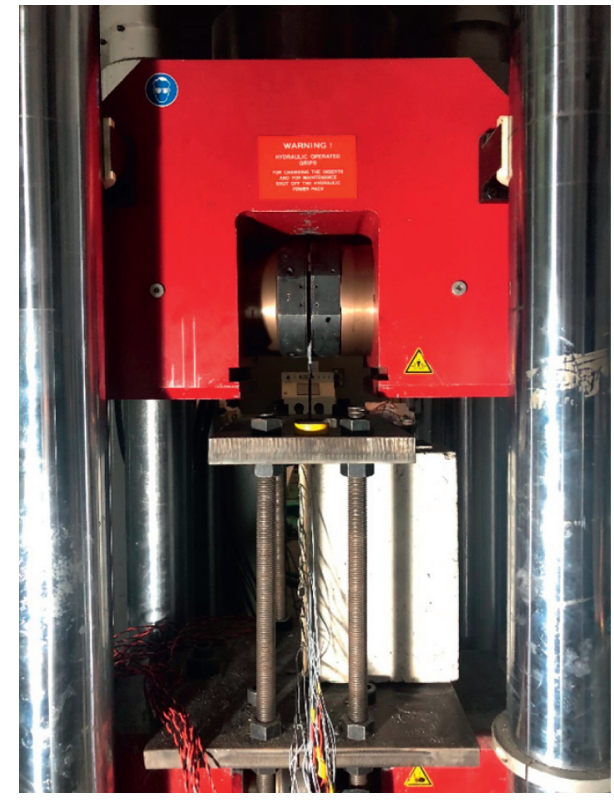

FIGURE 5: Specimen installation.

modes are obtained, as shown in Figure 7 for specimen $S_{1}$. During static loading, a relative slip $\Delta \omega$ of the BFRP grid to the concrete can be calculated as

$$
\Delta \omega=\omega-\varepsilon_{0} l_{0},
$$

where $\omega$ is the total slip of the loading end under the load, $\varepsilon_{0}$ is the strain measured by strain gauge $G_{1}$ in the nonbonding area of the BFRP grid, and $l_{0}$ is the length of the nonbonding area with a value of $200 \mathrm{~mm}$.

During the initial loading phase, $\Delta \omega$ increases approximately linearly with increased loading, indicating that the interface between the BFRP grid and concrete are in an elastic state. At this time, the bonding state is good with no interface cracks or cracks on the mortar surface. When the load reaches about $66 \%$ of the failure loading, there is a small platform in the amount of slip. The first crack appears on the outer surface of mortar near the loading end, local peeling occurs at the interface above the first crack, and $\Delta \omega$ continues to increase linearly with increased load. When the load reaches about $75 \%$ of the failure loading, a small platform appears again in the slip amount, a second crack occurs on the outer mortar surface, and the interface peels to the second crack. Because the direct peeling of the BFRP grid from the concrete is discontinuous, the platform phase appears intermittently on the loading-slip curve and $\Delta \omega$ continues to increase linearly with loading in each phase until the next platform appears. When the loading increases to $86 \%$ of the failure loading, a third small platform appears, which corresponds to a third crack on the outer mortar surface. With increased load, the interface crack between the BFRP grid and concrete expands to a certain length. In this case, the remaining bonding length is insufficient to support the increased load and slipping at the bonding end and $\Delta \omega$ increases rapidly until FRP grid peeling failure occurs. When the load reaches the peeling load, two more cracks appear on the mortar surface at the moment of failure.

3.2. Fatigue Tests. According to the results of the static loading tests, the average ultimate bonding load of the interface is $20.1 \mathrm{kN}$. Fatigue tests of BFRP grid-concrete interfaces were performed on specimens F-1-F-6. The test procedure and results are shown in Table 1.

The fatigue failure mode of the BFRP grid-concrete interface under high-loading conditions is peeling failure, which is consistent with the failure mode under static loading. When the loading level is low, the fatigue failure mode transforms to fatigue fracture of the BFRP grid. These two failure modes are shown in Figure 8. Fatigue failure of materials and components usually occurs at their weakest 


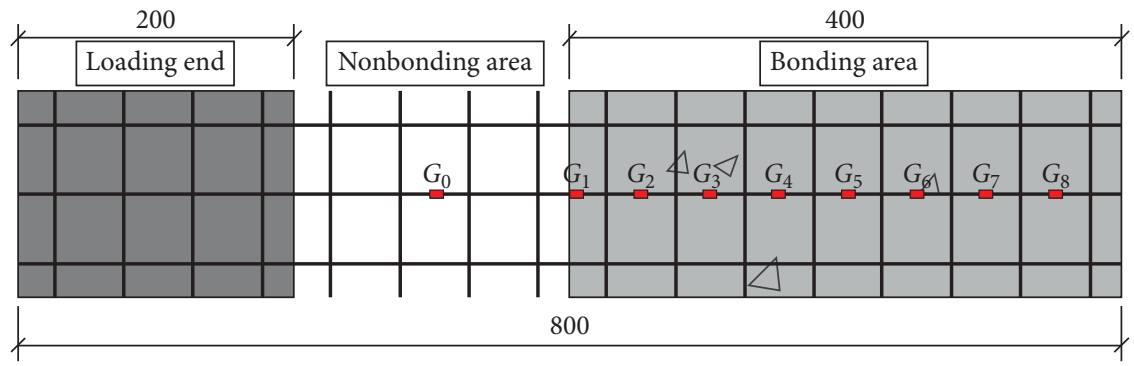

Figure 6: Arrangement of strain gauges on the BFRP grid.

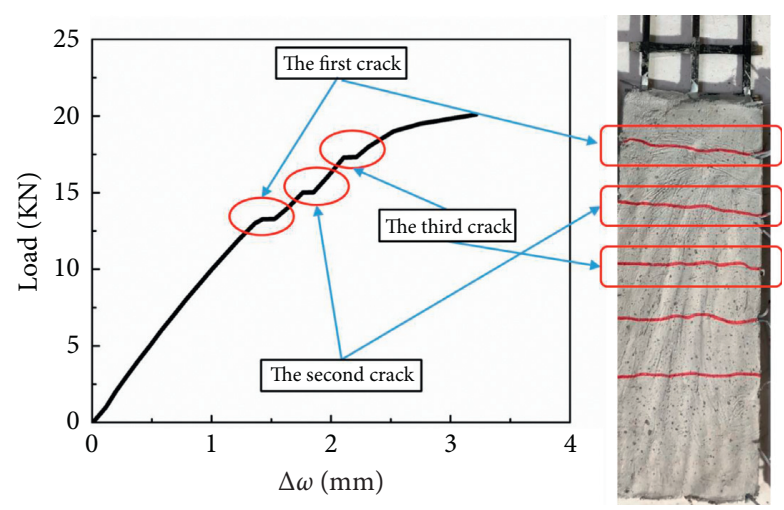

FIGURE 7: Loading-relative slip curve and failure mode of the BFRP grid under static loading.

TABLE 1: Fatigue test results of BFRP grid-concrete interface.

\begin{tabular}{|c|c|c|c|c|c|}
\hline $\begin{array}{l}\text { Specimen } \\
\text { number }\end{array}$ & $\begin{array}{l}\text { Loading level } \\
S=P_{\max } / P_{u}\end{array}$ & $\begin{array}{l}\text { Upper limit of loading } \\
\qquad P_{\max }(\mathrm{kN})\end{array}$ & $\begin{array}{l}\text { Lower limit of loading } \\
\qquad P_{\min }(\mathrm{kN})\end{array}$ & $\begin{array}{l}\text { Limit fatigue life } N_{f} \\
\text { (times) }\end{array}$ & $\begin{array}{l}\text { Failure } \\
\text { mode }\end{array}$ \\
\hline F-1 & 0.84 & 16.88 & 3.02 & 354 & \multirow{3}{*}{$\begin{array}{l}\text { Peeling } \\
\text { failure }\end{array}$} \\
\hline $\mathrm{F}-2$ & 0.80 & 16.08 & 3.02 & 3561 & \\
\hline F-3 & 0.76 & 15.28 & 3.02 & 12358 & \\
\hline F-4 & 0.72 & 14.47 & 3.02 & 103674 & \multirow{3}{*}{$\begin{array}{l}\text { Grid } \\
\text { fracture }\end{array}$} \\
\hline F-5 & 0.68 & 13.67 & 3.02 & 216459 & \\
\hline F-6 & 0.64 & 12.86 & 3.02 & 533292 & \\
\hline
\end{tabular}

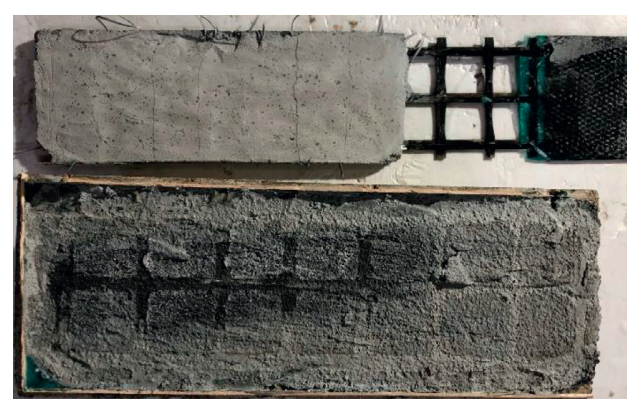

(a)

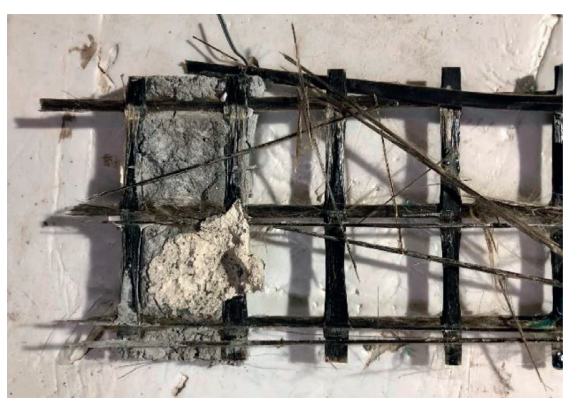

(b)

FIgURE 8: Failure mode of the BFRP grid under fatigue loading. (a) The interface peeling failure. (b) Fatigue fracture of the BFRP grid.

points and is caused by the accumulation of fatigue damage. $\Sigma D_{g}$ and $\Sigma D_{b}$ represent the cumulative damage of the BFRP grid and BFRP grid-concrete interface during fatigue, respectively. When the loading level is high (i.e., $\Sigma D_{g}<\Sigma D_{b}$ ), the interface failure mode is peeling failure of the interface.
When the loading level is low (i.e., $\Sigma D_{g}>\Sigma D_{b}$ ), the interface failure mode is fatigue fracture of the BFRP grid.

The $S$-N curve (fatigue life curve), first proposed by the "Father of Fatigue Test" August Wöhler, represents the relationship between applied material stress and fatigue life 
and is the basis for the prediction of fatigue life and fatigueresistant design of relevant components. More advanced $S-N$ curve expressions involve a power function formula (double logarithmic formula) and exponential function formula (single logarithmic formula). However, previous studies have shown that fatigue life of FRP-concrete interfaces and stress level obey a single logarithmic formula [39, 40]. We therefore also use a single logarithmic formula to characterize the $S-N$ curve of the FRP grid-concrete interface (Figure 9).

Figure 9 shows that the linear law of the $S$ - $N$ curves is different for different fatigue failure modes. Numerical fittings on fatigue test specimens with interfacial peeling failure (F-1, F-2, and F-3) and fatigue fracture of the BFRP grid (F4 , F-5, and F-6) were separated to obtain the $S-N$ curve expressions under different failure modes. The intersection of the two $S-N$ curves is interpreted to represent the critical point of the two fatigue failure modes (where $S=0.721$ and $N=10^{6}$ ). The expression of the $S-N$ curve between interface fatigue life and stress level can be expressed as

$$
\begin{cases}S=0.971-0.050 \lg N, & S>0.721 \\ S=1.281-0.112 \lg N, & S \leq 0.721 .\end{cases}
$$

3.3. Evolution of Relative Interface Slipping during Fatigue. Different fatigue failure modes inevitably lead to differences in the evolution of relative slip of the interface during the fatigue process. The real-time relative slip of the BFRP gridconcrete interface during fatigue can also be calculated by equation (1). The curves of the relative slip of BFRP gridconcrete interface with fatigue times for each specimen are shown in Figure 10. For the three fatigue specimens that show the interface peeling failure mode (F-1, F-2, and F-3) $(S>0.721), \Delta \omega$ can be divided into three stages with increasing fatigue time. The phase characteristic of relative slip is similar to the results obtained by Zheng et al. [41]. The first stage is the initial slip stage, which accounts for about $10 \%$ of the fatigue life. At this stage, $\Delta \omega$ increases rapidly with increasing fatigue time. This is caused by the appearance and rapid development of initial interface cracks under initial fatigue loading. The second stage is the stable slip stage, which accounts for about $80 \%$ of the fatigue life. $\Delta \omega$ increases steadily with increasing fatigue time and the increasing rate slows down compared with the initial slip stage. In this stage, the interface crack growth of the BFRP gridconcrete bonding interface tends to be stable. The third stage is the accelerated failure stage, which accounts for about $10 \%$ of the fatigue life. At this stage, $\Delta \omega$ increases significantly with increasing fatigue time. This is because peeling of the BFRP grid-concrete interface develops rapidly and the remaining bonding length of the interface is insufficient to support the peeling load.

For the three fatigue specimens that undergo fatigue fracture of the BFRP grid (F-4, F-5, and F-6) $(S \leq 0.721), \Delta \omega$ also shows an initial slip stage and a stable slip stage with increasing fatigue time. Because no interface peeling failure occurs, $\Delta \omega$ changes little in the later stable slip, and no accelerated failure stage occurs.

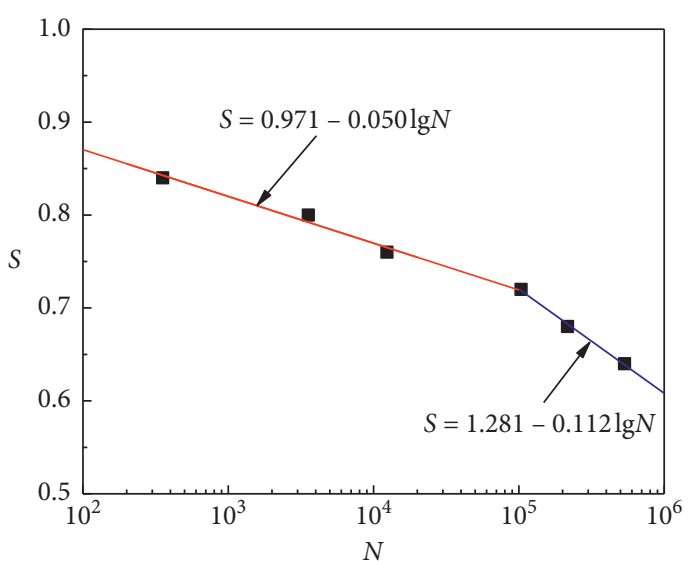

FIgURE 9: $S-N$ curve of the FRP grid-concrete interface.

3.4. Evolution of Interface Strain and Effective Bonding Length. Figure 11 shows the strain distribution curves of the BFRP grid as a function of bonding length under fatigue loading. Each curve shows that fatigue loading reaches an upper limit after a certain extent of fatigue time. Under high loading $(S>0.721)$, specimens F-1, F-2, and F-3 show sufficient bonding between the BFRP grid and concrete during the first loading and strain decreases rapidly with increasing distance from the bonding end of the BFRP grid. When the fatigue load reaches a certain value, the ability to transmit shear stress decreases owing to the gradual fatigue degradation of the bonding between the BFRP grid near the bonding end and the concrete. The strain attenuation slows down over a certain range near the bonding end, and the effective force transmission area (from the front end of interfacial peeling crack to the region where the strain approaches zero) begins to move to the free end. With increasing fatigue time, the bonding end area suffers adhesive failure and the interface only transmits shear stress by friction. The effective force transmission area also moves towards the free end, and the strain attenuation continues to slow down, eventually causing complete peeling failure of the interface. This phenomenon has also been demonstrated by the other investigator [42]. Under low loading $(S \leq 0.721)$, specimens F-4, F-5, and F-6 show similar interface strain evolution in the initial loading as those under high loading. However, with increasing fatigue time, the effective force transmission area slowly develops to the free end. The length of the effective force transmission area remains unchanged. When fatigue failure occurs, strain at the free end changes only slightly from that before fatigue.

The effective bonding length of the interface under fatigue load can be determined by the distribution curves of BFRP grid strain along the bonding length during the fatigue process [43]. The length of effective force transmission area can be used to characterize the effective bonding length of an interface $l_{e}$. Figure 11 shows that $l_{e}$ of samples under high loading gradually decreases with increasing fatigue time owing to the continuous expansion of interface cracks and interface peeling. When the remaining bonding length is insufficient to withstand the peeling load, peeling failure of the interface occurs. The effective bonding length of the low- 


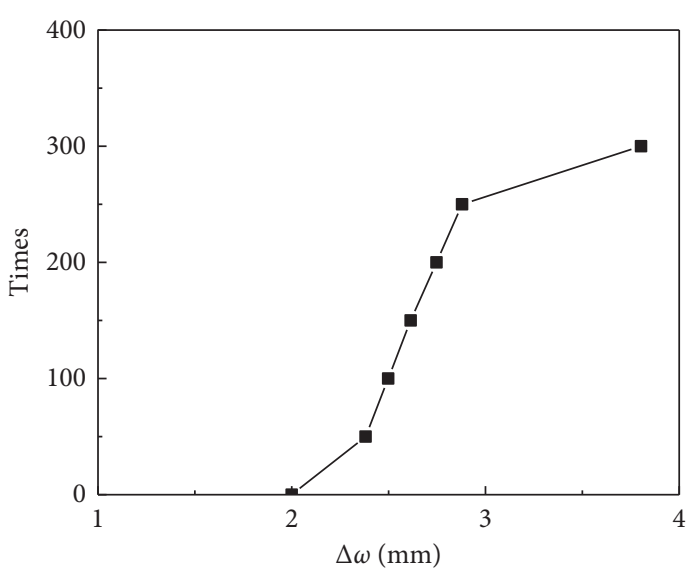

(a)

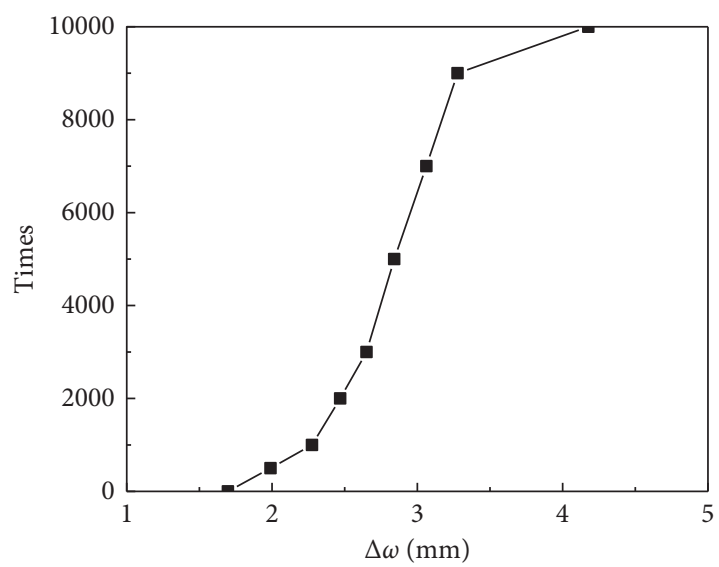

(c)

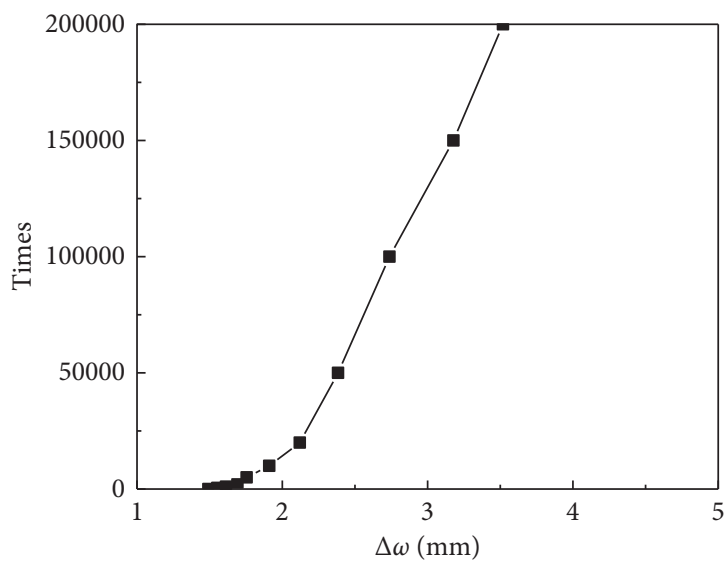

(e)

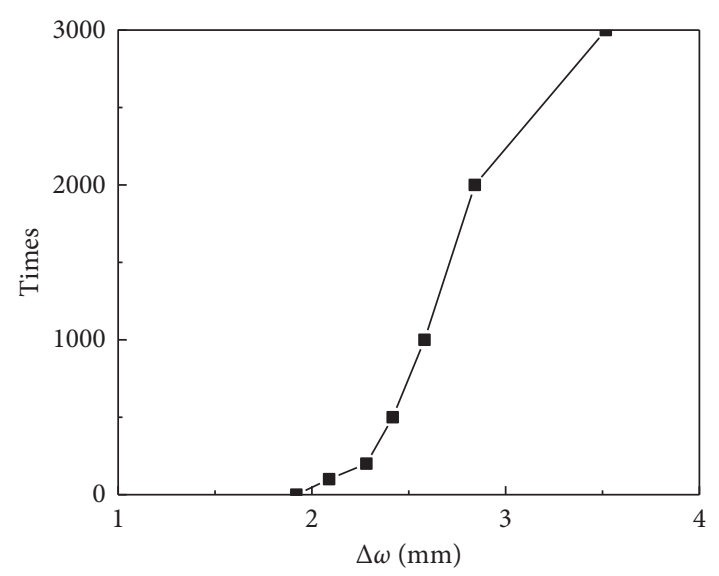

(b)

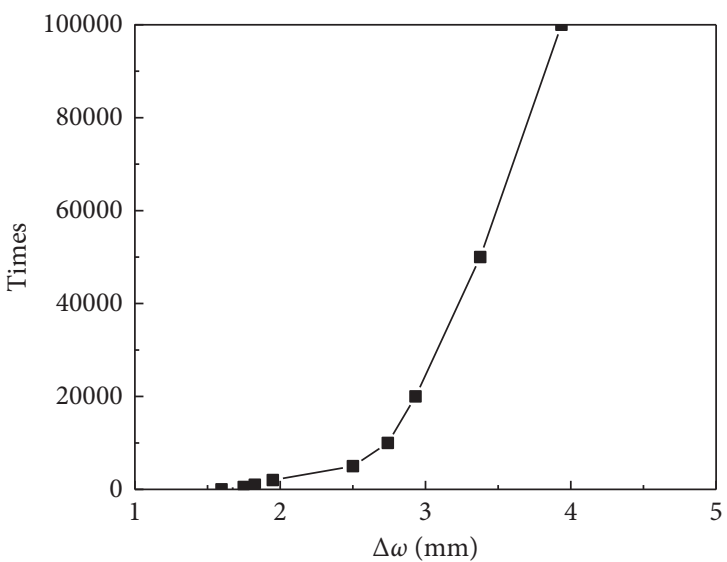

(d)

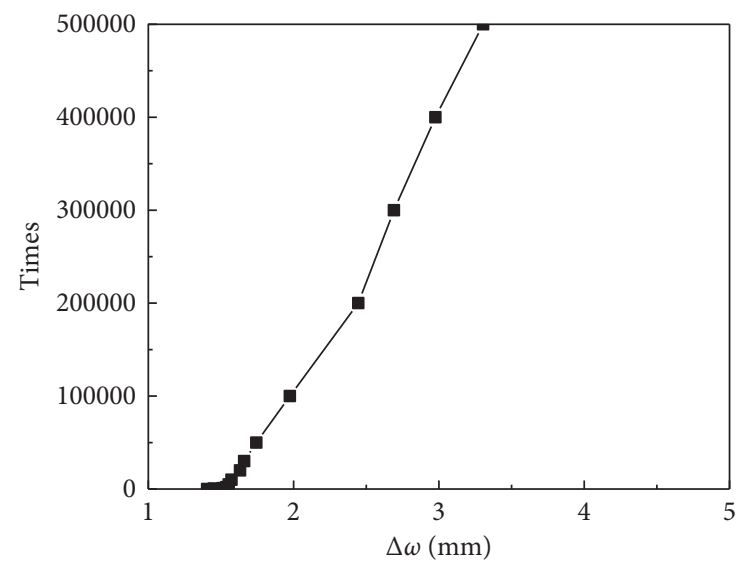

(f)

FIGURE 10: Relative slip curves of BFRP grid-concrete interface as a function of fatigue time. (a) F-1. (b) F-2. (c) F-3. (d) F-4. (e) F-5. (f) F-6.

load samples increases slightly with fatigue time and then remains essentially unchanged. This can be explained by a small amount of peeling failure that occurs under low loading at the end of the bonding area. With increasing fatigue time, the bonding performance of the interface remains stable, and the interface fatigue gradually changes to BFRP grid fatigue with the length sum of unbounded area and bonding end with peeling failure. 

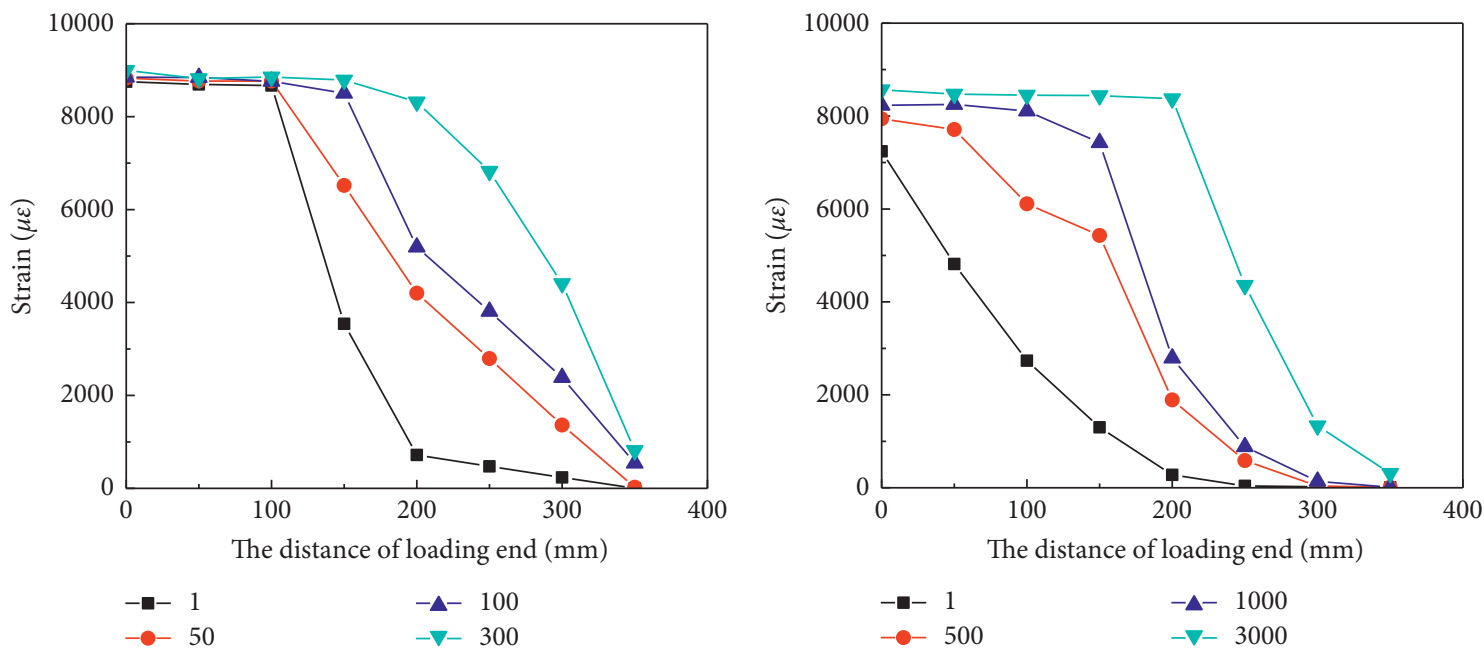

(a)

(b)
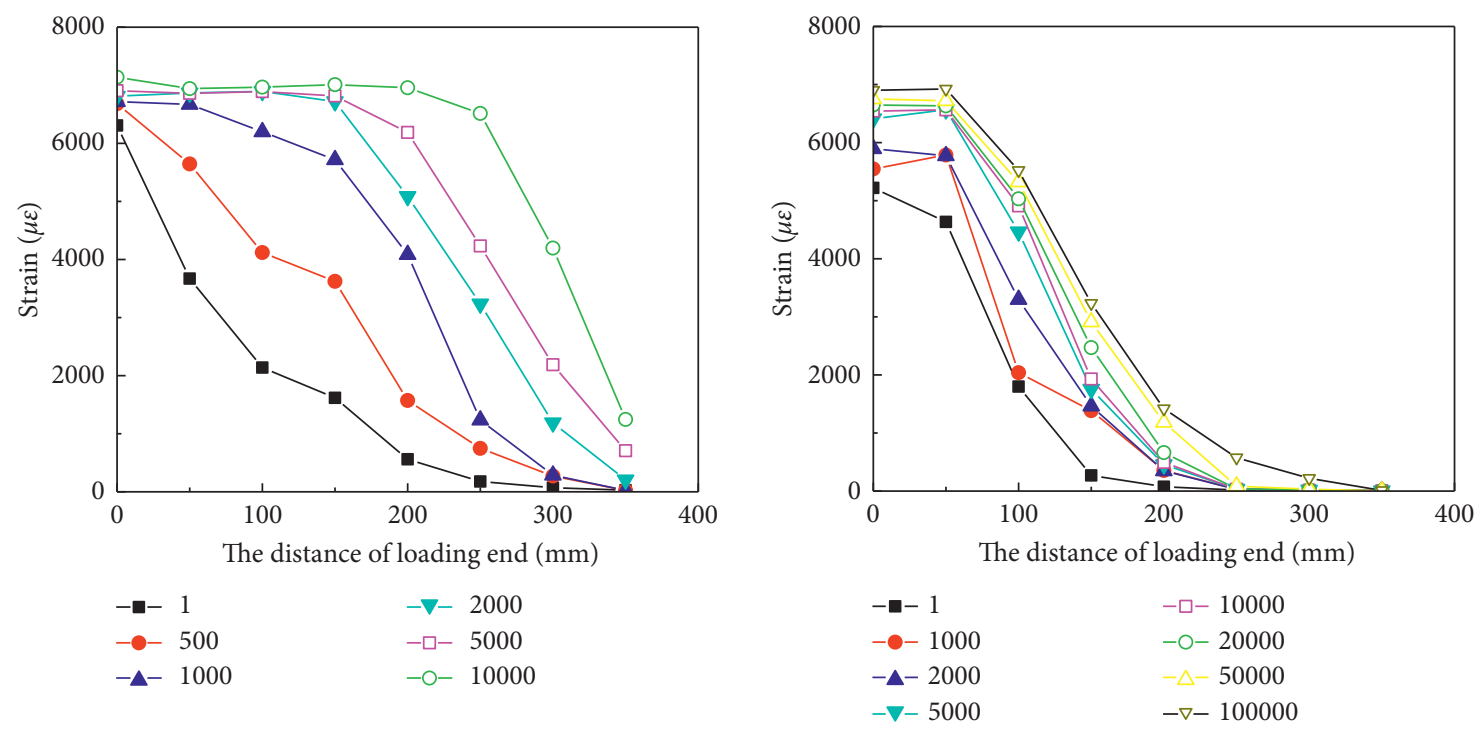

(c)

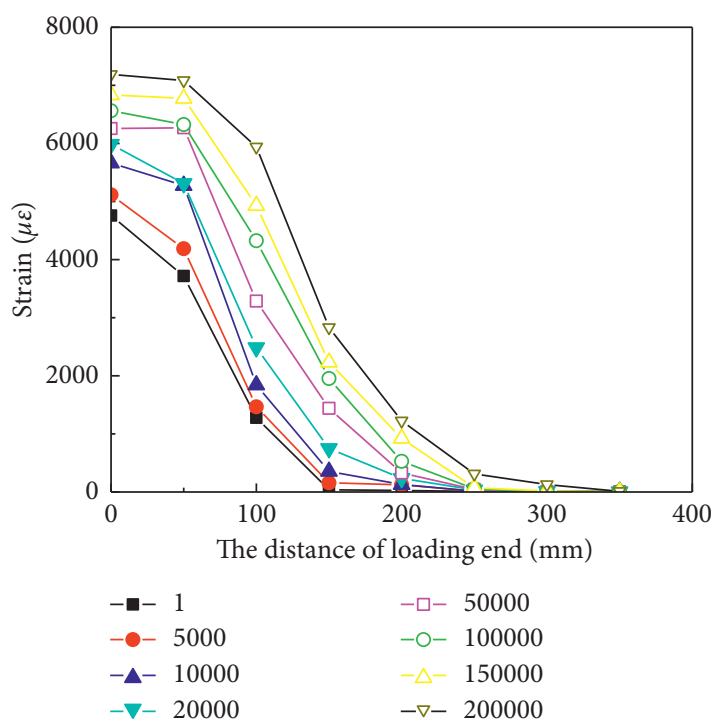

(e)

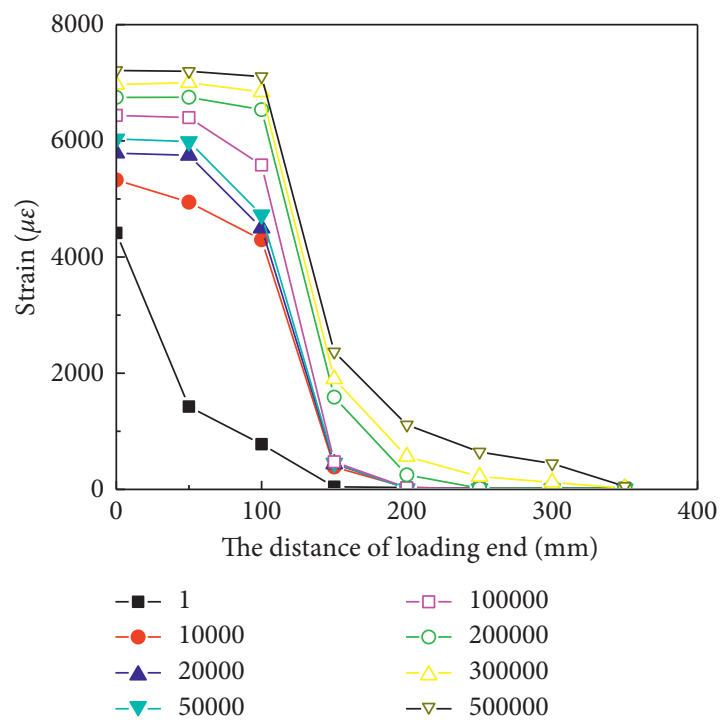

(f)

FIGURE 11: Distribution of BFRP grid strain as a function of bonding length under fatigue loading. (a) F-1. (b) F-2. (c) F-3. (d) F-4. (e) F-5. (f) F-6. 


\section{Conclusions}

A series of concrete specimens reinforced by BFRP grid and polymer mortar were prepared for both static loading and fatigue loading tests using a servohydraulic dynamic fatigue testing system. Based on the results of the static loading tests, various fatigue tests of interfaces between the BFRP grid and concrete were conducted under different loading levels. Under high loading level, the BFRP grid-concrete interface undergoes peeling failure, and under low loading level, the fatigue failure mode transforms to fatigue fracture of the BFRP grid. The $S$ - $N$ curves under different failure modes were obtained. The intersection of the two $S-N$ curves is interpreted to represent the critical point of the two fatigue failure modes. The evolution of relative slip of the interface during fatigue with high loading level can be described to have three stages. The relative slip first increases rapidly in the initial slip stage, then increases steadily during the stable slip stage, and then increases significantly in the accelerated failure stage. For specimens under low loading level, the relative slip also experiences the former two stages and then changes little.

The evolution of interface strain during fatigue was also investigated. For specimens under high loading level, the effective force transmission area moves towards the free end and the strain attenuation continues to slow down with increasing fatigue time, eventually causing the complete peeling failure of the interface. Moreover, it can be concluded that for specimens under high loading level, the effective bonding length of the interface remains essentially unchanged with increasing fatigue time, whereas for specimens under low loading level, the effective bonding length of the interface shows an increasing trend with fatigue time.

Future studies should include tests under a wider range of loading conditions using various types of reinforced concrete to investigate interface fatigue performance and verify the preliminary conclusion drawn in this study. A bonding slip model can be further developed to investigate the slip mechanism.

\section{Data Availability}

The data used to support the findings of this study are included within the article.

\section{Conflicts of Interest}

The authors declare that there are no conflicts of interest regarding the publication of this paper.

\section{Acknowledgments}

This research was funded by the National Key Research and Development Program of China (no. 2017YFC0805900), the Natural Science Foundation of Jiangsu Province (grant no. BK20191302), the Innovative Venture Technology Investment Project of Hunan Province (2018GK5028), the Fund for Distinguished Young Scientists of Jiangsu Province (BK20190013), the National Natural Science Foundation of
China (no. 51578140), the Postgraduate Research \& Innovation Program of Jiangsu Province, and the Fundamental Research Funds for Southeast University (no. KYLX15_0084), as well as by a project funded by the Priority Academic Program Development of Jiangsu Higher Education Institutions (PAPD, no. CE02-2-8).

\section{References}

[1] C. E. Bakis, L. C. Bank, V. L. Brown et al., "Fiber-reinforced polymer composites for construction-state-of-the-art review," Journal of Composites for Construction, vol. 6, no. 2, pp. 73-87, 2002.

[2] V. Lopresto, C. Leone, and I. De Iorio, "Mechanical characterisation of basalt fibre reinforced plastic," Composites Part B: Engineering, vol. 42, no. 4, pp. 717-723, 2011.

[3] L. D. Lorenzis and J. G. Teng, "Near-surface mounted FRP reinforcement: an emerging technique for strengthening structures," Composites Part B: Engineering, vol. 38, no. 2, pp. 119-143, 2007.

[4] R. Sen, "Developments in the durability of FRP-concrete bond," Construction and Building Materials, vol. 78, pp. 112-125, 2015.

[5] F. M. Mukhtar, R. M. Faysal, and R. M. Faysal, "A review of test methods for studying the FRP-concrete interfacial bond behavior," Construction and Building Materials, vol. 169, pp. 877-887, 2018.

[6] N. T. K. Al-Saadi, A. Mohammed, R. Al-Mahaidi, and J. Sanjayan, "A state-of-the-art review: near-surface mounted FRP composites for reinforced concrete structures," Construction and Building Materials, vol. 209, pp. 748-769, 2019.

[7] J.-G. Dai, S. Munir, and Z. Ding, "Comparative study of different cement-based inorganic pastes towards the development of FRIP strengthening technology," Journal of Composites for Construction, vol. 18, no. 3, Article ID A4013011, 2013.

[8] R. Contamine and A. Si Larbi, "Development of a textile reinforced concrete (TRC) to retrofit reinforced concrete structures," European Journal of Environmental and Civil Engineering, vol. 20, no. 6, pp. 626-642, 2016.

[9] R. Azam, K. Soudki, J. S. West, and M. Noël, "Strengthening of shear-critical RC beams: Alternatives to externally bonded CFRP sheets," Construction and Building Materials, vol. 151, pp. 494-503, 2017.

[10] O. Awani, T. El-Maaddawy, and N. Ismail, "Fabric-reinforced cementitious matrix: a promising strengthening technique for concrete structures," Construction and Building Materials, vol. 132, pp. 94-111, 2017.

[11] N. M. Ali, X. Wang, Z. Wu, and A. Y. Hassanein, "Basalt fiber reinforced polymer grids as an external reinforcement for reinforced concrete structures," Journal of Reinforced Plastics and Composites, vol. 34, no. 19, pp. 1615-1627, 2015.

[12] L. C. Bank, M. G. Oliva, J. S. Russell et al., "Double-layer prefabricated FRP grids for rapid bridge deck construction: case Study," Journal of Composites for Construction, vol. 10, no. 3, pp. 204-212, 2006.

[13] L. Righetti, V. Edmondson, M. Corradi, and A. Borri, "Fiberglass grids as sustainable reinforcement of historic masonry," Materials, vol. 9, no. 7, p. 603, 2016.

[14] W.-Y. Gao, K.-X. Hu, J.-G. Dai, K. Dong, K.-Q. Yu, and L.-J. Fang, "Repair of fire-damaged RC slabs with basalt fabric-reinforced shotcrete," Construction and Building $\mathrm{Ma}$ terials, vol. 185, pp. 79-92, 2018. 
[15] F. Ceroni, A. Bonati, V. Galimberti, and A. Occhiuzzi, "Effects of environmental conditioning on the bond behavior of FRP and FRCM systems applied to concrete elements," Journal of Engineering Mechanics, vol. 144, no. 1, Article ID 04017144, 2018.

[16] L. Ombres, "Analysis of the bond between fabric reinforced cementitious mortar (FRCM) strengthening systems and concrete," Composites Part B: Engineering, vol. 69, pp. 418426, 2015.

[17] T. D’Antino, C. Carloni, L. H. Sneed, and C. Pellegrino, "Fatigue and post-fatigue behavior of PBO FRCM-concrete joints," International Journal of Fatigue, vol. 81, pp. 91-104, 2015.

[18] B. Wang, K. Uji, T. Wu, H. Dai, D. Yan, and R. Guo, "Experimental investigation of stress transfer and failure mechanism between existing concrete and CFRP grid-sprayed PCM," Construction and Building Materials, vol. 215, pp. 43-58, 2019.

[19] A. D'Ambrisi, L. Feo, and F. Focacci, "Experimental analysis on bond between PBO-FRCM strengthening materials and concrete," Composites Part B: Engineering, vol. 44, no. 1, pp. 524-532, 2013.

[20] O. Awani, A. E. Refai, and T. El-Maaddawy, "Bond characteristics of carbon fabric-reinforced cementitious matrix in double shear tests," Construction and Building Materials, vol. 101, pp. 39-49, 2015.

[21] M. Leone, M. A. Aiello, A. Balsamo et al., "Glass fabric reinforced cementitious matrix: tensile properties and bond performance on masonry substrate," Composites Part B: Engineering, vol. 127, pp. 196-214, 2017.

[22] B. Li, H. Xiong, J. Jiang, and X. Dou, "Tensile behavior of basalt textile grid reinforced engineering cementitious composite," Composites Part B: Engineering, vol. 156, pp. 185-200, 2019.

[23] P. Larrinaga, C. Chastre, H. C. Biscaia, and J. T. San-José, "Experimental and numerical modeling of basalt textile reinforced mortar behavior under uniaxial tensile stress," Materials \& Design, vol. 55, pp. 66-74, 2014.

[24] E. Bertolesi, F. G. Carozzi, G. Milani, and C. Poggi, "Numerical modeling of fabric reinforce cementitious matrix composites (FRCM) in tension," Construction and Building Materials, vol. 70, pp. 531-548, 2014.

[25] Y.-Z. Zheng, W.-W. Wang, and J. C. Brigham, "Flexural behaviour of reinforced concrete beams strengthened with a composite reinforcement layer: BFRP grid and ECC," Construction and Building Materials, vol. 115, pp. 424-437, 2016.

[26] H. Fang, X. Xu, W. Liu et al., "Flexural behavior of composite concrete slabs reinforced by FRP grid facesheets," Composites Part B: Engineering, vol. 92, pp. 46-62, 2016.

[27] X. Yang, W.-Y. Gao, J.-G. Dai, Z.-D. Lu, and K.-Q. Yu, "Flexural strengthening of RC beams with CFRP grid-reinforced ECC matrix," Composite Structures, vol. 189, pp. 9-26, 2018.

[28] W. Meng, K. H. Khayat, and Y. Bao, "Flexural behaviors of fiber-reinforced polymer fabric reinforced ultra-high-performance concrete panels," Cement and Concrete Composites, vol. 93, pp. 43-53, 2018.

[29] X.-H. Li, G. Wu, S. Wang, and X.-H. Yu, "Flexural behavior of hollow-core slabs strengthened with prestressed basalt FRP grids," Journal of Composites for Construction, vol. 23, no. 3, Article ID 04019016, 2019.

[30] R. Guo, L. H. Cai, S. Hino, and B. Wang, "Experimental study on shear strengthening of RC beams with an FRP grid-PCM reinforcement layer," Applied Sciences, vol. 9, no. 15, p. 2984, 2019.

[31] R. Azam, K. Soudki, J. S. West, and M. Noël, "Shear strengthening of RC deep beams with cement-based composites," Engineering Structures, vol. 172, pp. 929-937, 2018.

[32] A. Garofano, F. Ceroni, and M. Pecce, "Modelling of the inplane behaviour of masonry walls strengthened with polymeric grids embedded in cementitious mortar layers," Composites Part B: Engineering, vol. 85, pp. 243-258, 2016.

[33] F. Ceroni and P. Salzano, "Design provisions for FRCM systems bonded to concrete and masonry elements," Composites Part B: Engineering, vol. 143, pp. 230-242, 2018.

[34] R. Guo, Y. Pan, L. Cai, and S. Hino, "Bonding behavior of CFRP grid-concrete with PCM shotcrete," Engineering Structures, vol. 168, pp. 333-345, 2018.

[35] Chinese Standard GB 50010, Code for Design of Concrete Structures. GB50010-2010, China Building Industry Press, Beijing, China, 2010, in Chinese.

[36] American Society for Testing and Materials (ASTM), Standard Test Method for Tensile Properties of Polymer Matrix Composite Materials D3039/D3039M-17, American Society for Testing and Materials, West Conshohocken, PA, USA, 2017.

[37] American Society for Testing and Materials (ASTM), Standard Test Method for Tensile Properties of Thin Plastic Sheeting D882-18, American Society for Testing and Materials, West Conshohocken, PA, USA, 2018.

[38] American Society for Testing and Materials (ASTM), Standard Test Method for Tension-Tension Fatigue of Polymer Matrix Composite Materials D3479/D3479M-12, American Society for Testing Testing and Materials, West Conshohocken, PA, USA, 2012.

[39] J. Xie, J. Li, Z. Lu, and H. Zhang, "Experimental Study on Fatigue Behaviour of BFRP-Concrete Bond Interfaces under Bending Load," Shock and Vibration, vol. 2018, Article ID 7497061, 11 pages, 2018.

[40] W. Zhang, "Experimental study on fatigue behaviour of CFRP plates externally bonded to concrete substrate," Structural Concrete, vol. 17, no. 2, pp. 235-244, 2016.

[41] X. H. Zheng, P. Y. Huang, Q. Han, and G. M. Chen, "Bond behavior of interface between CFL and concrete under static and fatigue load," Construction and Building Materials, vol. 52, pp. 33-41, 2014.

[42] K. Li, S.-Y. Cao, and X.-L. Wang, "Experimental study on fatigue endurance of the CFRP-concrete interface," Journal of Composites for Construction, vol. 19, no. 4, Article ID 04014075, 2015.

[43] J.-T. Zhu, X.-L. Wang, X.-D. Kang, and K. Li, "Analysis of interfacial bonding characteristics of CFRP-concrete under fatigue loading," Construction and Building Materials, vol. 126, pp. 823-833, 2016. 